\title{
EVALUATION OF CEPHALIC INDEX IN FEMALES OF WESTERN UP REGION BY SIMPLE REGRESSION ANALYSIS
}

Sumita Agarwal ${ }^{1}$, S.K. Jain ${ }^{2}$, S.K. Agarwal ${ }^{3}$

\section{HOW TO CITE THIS ARTICLE:}

Sumita Agarwal, S.K. Jain, S.K. Agarwal. "Evaluation of Cephalic Index in Females of Western UP Region by Simple Regression Analysis". Journal of Evolution of Medical and Dental Sciences 2014; Vol. 3, Issue 03, January 20; Page: 718-725, DOI: 10.14260/jemds/2014/1892

ABSTRACT: Population can be classified by evaluation of cephalic index. Metric evaluation of cephalic index can be done generation of simple regression equation. In this study we evaluated horizontal cephalic index of females of western UP region, which forms a base line study of cephalic index of this region, and more so over it reflects the intelligence level, socioeconomic status, dietary adequacies (inadequacies) and any ailment of ill health, which is reflected in the values of cephalic index. This base line study will also help orthodontists, plastic surgeons and anthropologists in cranio-facial reconstruction. AIMS \& OBJECTIVE: The aim of this study is to generate a simple regression equation for cephalic index of females of western UP region using two variables. MATERIAL \& METHODS: This exploratory study was conducted on 400 female students (17-25yrs) of TMMC\&RC, Moradabad, employing purposive sampling method, using Pearson's coefficient, and generating simple regression equation. Spreading caliper was the instrument used in this study. RESULT: Following Simple regression equation $=133.71+(-2.96) 17.53$ was generated using maximum head breadth $(143.20$ $\mathrm{mm}$ ). CONCLUSION: We concluded our study by generating the simple regression equation for evaluation of cephalic index of females of western up region (81.83\%).(Brachycephalic).

KEYWORDS: PEARSON'S COEFFICIENT, SIMPLE REGRESSION EQUATION, CEPHALIC INDEX, \& SPREADING CALIPERS.

INTRODUCTION: Human body dimensions are affected by ecological, geographical, racial, gender, and age factors 1,2 . In order to achieve racial assessment, and discriminate among populations metrical studies have long been practiced. Cephalic index is an important parameter for classifying populations. Internationally accepted techniques of anthropometry have promoted a large number of comparable data for males and females ${ }^{3}$. This is supported by the great range of cranial indices and shapes in racial groups however sexual differences are minimal 4.

Anthropologists classified population on the basis of anthropometric data collected from various subcontinents of the world. 5

Cephalometry is a branch of anthropometry in which the anatomical dimensions of head and face are measured. Cephalometry continues to be the most versatile technique in the investigation of the craniofacial skeleton because of its validity and practicality. 6

On the basis of Horizontal cephalic index, head shapes group to four international categories, that including

Dolichocephalic,

Brachycephalic,

Mesocephalic

Hyper brachycephalic ${ }^{4}$. 


\section{ORIGINAL ARTICLE}

(Williams et al, 1995) determined on the basis of international anatomical descriptions of cephalic index (CI) (\%) 4

Dolichocephalic $<74.9$

Mesocephalic 75-79.9

Brachycephalic 80-84.9

Hyper-brachycephalic 85-89.9

Dolichocephalic person have otitis media less often than brachycephalic persons ${ }^{7}$. It has also been reported that individuals with Alpert's syndrome are hyper- brachycephalic ${ }^{8}$. Many studies have been conducted in various parts of India applying the techniques of anthropometry ${ }^{9}$. While there are many measures of association for variables which are measured at the ordinal or higher level of measurement, correlation is the most commonly used approach. Correlation summarizes the relationship between two variables in a single number called the correlation coefficient. A correlation coefficient close to plus 1 means a positive relationship between the two variables, with increases in one of the variables being associated with increases in the other variable. A correlation coefficient close to -1 indicates a negative relationship between two variables, with an increase in one of the variables being associated with a decrease in the other variable. Most commonly used correlation coefficient is Pearson's (r).

AIMS \& OBJECTIVES: While many studies have been conducted on the estimation of stature from different body parts 10-16 including arms and legs, hands and feet, intact vertebral column, as well as head, face and trunk, no study has been conducted on assessment of cephalic index by just knowing one of its variable (maximum antero-posterior length), in the literature cited so far and, therefore we conducted this study to see whether, there exists a correlation between (maximum antero-posterior length), and (cephalic index) and if there exists a relationship, Pearson's coefficient $r=(-1)$ or $(+1)$ and then estimation of cephalic index by derivation of simple regression equation of 400 females of age group (18-25 yrs.) of western up region.

\section{MATERIAL \& METHODS:}

Place of study: This study was conducted in department of Anatomy, Teerthankar Mahaveer Medical College \& Research Centre, Teerthankar Mahaveer University, Moradabad. India.

Number of subjects: 400 students

Age group: 17-25 were chosen for study.

Sex: Female

Sampling method: Purposive sampling method. This sampling is best when we are studying a particular set of groups.

Statistical analysis: Using Pearson's coefficient, Descriptive statistical analysis and simple regression equation.

Study design: Exploratory study.

Exclusion criteria: Individuals with craniofacial anomalies

Measurements for maximum head length: Was taken from Glabella (a point above the root of the nose between the two superciliary arches) to Inion (a salient point of external occipital protuberance. 
Measurements for maximum head breadth: Was taken between two Porions (a point on the posterior root of the Zygomatic arch on the middle of the upper border of External acoustic meatus),

The data was calculated with Cephalic Index Formula as: C.I. = Maximum head breadth $/$ maximum head length $\times 100$ (Horizontal cephalic index).

Position of the Head: Head in anatomical position, using (Hrdlicka's method 1952), ${ }^{17}$.

Instrument: Measurements were taken with the help of "SPREADING CALIPERS".

All measurements were taken in centimeters to an accuracy of 0.10 .

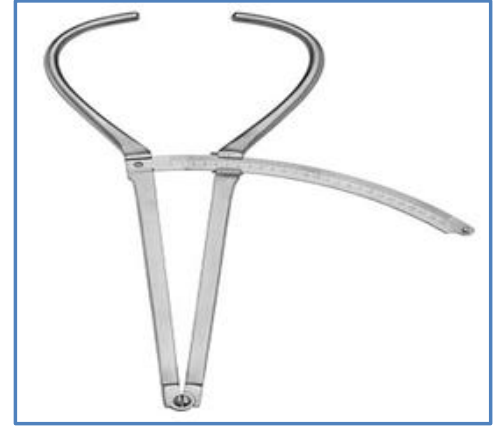

Fig. 1: SPREADING CALIPERS

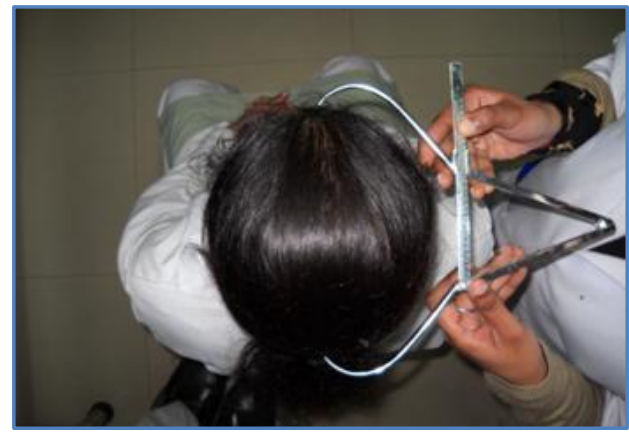

Fig. 2: Measurements for maximum head length

\section{RESULTS:}

\begin{tabular}{|l|c|}
\hline \multicolumn{2}{|c|}{ DESCRIPTIVE ANALYSIS OF } \\
MAX LENGTH OF HEAD FEMALE \\
\hline Mean & $17.53(\mathrm{~cm})$ \\
\hline Standard Error & 0.03 \\
\hline Median & 17.5 \\
\hline Mode & 17.4 \\
\hline Standard Deviation & 0.64 \\
\hline Sample Variance & 0.41 \\
\hline Kurtosis & 1.25 \\
\hline Skewness & -0.32 \\
\hline Range & 5.1 \\
\hline Minimum & 14.4 \\
\hline Maximum & 19.5 \\
\hline Sum & 6997.6 \\
\hline Count & 400 \\
\hline \multicolumn{2}{|c|}{ Table-1 } \\
\hline
\end{tabular}

\begin{tabular}{|l|c|}
\hline \multicolumn{2}{|c|}{ DESCRIPTIVE ANALYSIS OF } \\
MAX BREADTH OF HEAD FEMALE \\
\hline Mean & $14.32(\mathrm{~cm})$ \\
\hline Standard Error & 0.02 \\
\hline Median & 14.3 \\
\hline Mode & 14 \\
\hline Standard Deviation & 0.53 \\
\hline Sample Variance & 0.28 \\
\hline Kurtosis & 0.82 \\
\hline Skewness & 0.52 \\
\hline Range & 3.4 \\
\hline Minimum & 13.1 \\
\hline Maximum & 16.5 \\
\hline Sum & 5716.8 \\
\hline Count & 400 \\
\hline \multicolumn{2}{|c|}{ Table-2 } \\
\hline
\end{tabular}




\begin{tabular}{|l|c|}
\hline \multicolumn{2}{|c|}{$\begin{array}{c}\text { DESCRIPTIVE ANALYSIS OF } \\
\text { CEPHALIC INDEX FEMALE }\end{array}$} \\
\hline Mean & $81.66(\%)$ \\
\hline Standard Error & 0.170 \\
\hline Median & 81.66 \\
\hline Mode & 81.6 \\
\hline Standard Deviation & 3.40 \\
\hline Sample Variance & 11.601 \\
\hline Kurtosis & 0.026 \\
\hline Skewness & -0.057 \\
\hline Range & 18.19 \\
\hline Sum & 32584.39 \\
\hline Count Table-3 & 400 \\
\hline \multicolumn{2}{|c|}{} \\
\hline
\end{tabular}

\begin{tabular}{|c|c|}
\hline \multicolumn{2}{|c|}{ Regression Statistics } \\
\hline Multiple R & 0.558 \\
\hline R Square & 0.311 \\
\hline Adjusted R Square & 0.310 \\
\hline Standard Error & 2.828 \\
\hline Observations & 400 \\
\hline \multicolumn{2}{|c|}{ Table-4 } \\
\hline
\end{tabular}

Pearson's coefficient between maximum length of female head and cephalic index is -0.558 . This shows that there is definite relationship between maximum length of head and cephalic index. This gives us a value by which we calculated the cephalic index of female by using simple regression equation, of western region of Uttar Pradesh by just using maximum length of head.

\begin{tabular}{|c|c|c|}
\hline & Coefficients & Standard Error \\
\hline Intercept (a) & 133.71 & 3.88 \\
\hline $\mathrm{x}=17.53$ & (b) -2.96 & 0.22 \\
\hline
\end{tabular}

Where (a) intercept $=133.71$

(b) slope $=-2.96$

Simple regression equation $\mathrm{Y}=\mathrm{a}+\mathrm{bx}$

$=133.71+(-2.96) 17.53$

$=81.83$

So simple regression equation for evaluation of cephalic index from maximum length of head in females of western UP region is

$=133.71+(-2.96) 17.4$

$=81.83$

On the basis of above calculation the value of cephalic index in present study is $\mathbf{8 1 . 6 8 \%}$, which falls in the group of brachycephalic group of skulls ranging from (80-84.9). In all three (max. head length, max. head breadth and cephalic index kurtosis is less than 3 , which shows that The probability for extreme values is less than for a normal distribution, and the values are wider spread around the mean that is values show platykurtic distribution. In maximum head length and cephalic index values are less than 0 which shows most values are concentrated on the right of the mean, with extreme values to the left while in maximum head breadth it is more than 0 , which shows most values are concentrated on left of the mean, with extreme values to the right. 
DISCUSSION: In the present study the mean values of maximum head length, maximum head breadth and cephalic index are $17.53 \pm 0.64 \mathrm{~cm}, 14.32 \pm 0.53 \mathrm{~cm}$ and $81.66 \pm 3.40 \%$ respectively.

\begin{tabular}{|c|l|l|c|c|c|}
\hline S.N. & \multicolumn{1}{|c|}{ Area of study } & Authors & Year of study & $\begin{array}{c}\text { Head length } \\
\text { (mm) }\end{array}$ & $\begin{array}{c}\text { Head breadth } \\
\text { (mm) }\end{array}$ \\
\hline 1 & Western UP & present study & $\mathbf{2 0 1 3}$ & $\mathbf{1 7 5 . 3 0}$ & $\mathbf{1 4 3 . 2 0}$ \\
\hline 2 & Lativa & Nagle E et al 18 & 2005 & 183.3 & 145.8 \\
\hline 3 & Malaysian & Neglow WC 19 & 2009 & 173.4 & 149.4 \\
\hline 4 & Nigeria (North-Eastern) & Raji JM 20 & 2010 & 183.9 & 135.7 \\
\hline 5 & Nigeria (Ibibos) & Oladipo GS 21 & 2010 & 188 & 147 \\
\hline 6 & Punjabi Students & Mahajan A 22 & 2010 & 179 & 147.2 \\
\hline 7 & Nigeria & Maina MB 23 & 2011 & 183.53 & 135.47 \\
\hline 8 & Japanese & Hossain MG ${ }^{24}$ & 2011 & 180.12 & 147.8 \\
\hline 9 & Sri Lanka & Ilayperuma 25 & 2011 & 175 & 141.11 \\
\hline 10 & North India & Gupta et al 26 & 2013 & 177.74 & 136.19 \\
\hline
\end{tabular}

Racial characters are best defined in the skull 27,28.Cephalic index provides metrical recording of cranial features. ${ }^{28}$ and cephalometric data provides diagnostic comparison between ill and the normal population ${ }^{29}$. Population, age and gender specific data on cephalic indices give an indication of development of an individual and also identifies craniofacial anomalies ${ }^{30}$.The cephalic index value obtained in this study are valid for the age group (17-25 years). It has been stated that cranial dimensions varies with the age of the person. ${ }^{31,32}$

On the basis of above calculation the value of cephalic index in present study is $81.68 \%$, which falls in the group of brachycephalic group of skulls ranging from (80-84.9). In all three (max. head length, max. head breadth and cephalic index kurtosis is less than 3, which shows that the probability for extreme values is less than for normal distribution, and the values are wider spread around the mean that is values show platykurtic distribution. If max. head length and cephalic index values are less than 0 , this shows most values are concentrated on the right of the mean, with extreme values to the left while if max. head breadth it is more than 0 , which shows most values are concentrated on left of the mean, with extreme values to the right.

The mean cephalic index in different ethnic groups varies significantly in different zones ${ }^{33}$ According to 34 in tropical zones head is (dolichocephalic), but in temperate zones head is (mesocephalic or brachycephalic).

From the above table it is clear that value of head length in our study is more than Malaysian and Sri Lankans and lower than other studies mentioned above, which is almost non-significant statistically.

The mean horizontal cephalic index observed in this study (81.68) is higher than those observed for the Turkman:80.4 35, Mapuche individuals in Chile: $80.42{ }^{36}$, European people in Mediterranean area: 81.19, North Europeans: 79.72 37,38 and lower than native Fars:84.8 39 , Japanese: $87^{40}$ a finding that further reinforces the racial diversity in the cephalic index. 
In bio-statistics, linear regression is an approach to establish the relationship between a dependent variable $\mathrm{y}$ and one or more explanatory variables denoted $\mathrm{X}$. The case of one explanatory variable is called simple linear regression.

This relationship helps an anthropologist to calculate stature from mutilated and dismembered body parts with the aid of linear regression equations ${ }^{12,15}$

In the present study two parameters for evaluating cephalic index (maximum head length and maximum head breadth) are correlated with cephalic index as shown by evaluation of Pearson's coefficient $(-0.557821$ and 0.566172$)$ respectively. This confirms that we can create simple regression equation using any of the two parameters. In this study we used the maximum head length for evaluation.

By applying the formula

Cephalic index= Maximum head breadth/Maximum head length*100, we find the value of cephalic index 81.66 and also by evaluation of simple regression equation we calculated the value 81.83 which is statistically non-significant and both values come in the category of brachycephalic index.

CONCLUSION: We concluded our study with the fact that if a correlation exists between two variables, the simple regression equation can be generated and that simple regression equation can be applied to that racial and geographical area. On the same principal of biostatistics we created the simple regression equation for cephalic index for females of western Uttar Pradesh, India, which was not taken into consideration before this study. We hope that this analytical study will help other researchers to generate new correlations for anthropometric studies.

\section{REFERENCES:}

1. Golalipour et al. The shapes of head and face in normal male newborns in south-east of Caspian Sea (Iran-Gorgan). J Anat Soc India 2003;52:28-31

2. Rajlakshmi et al. Cephalic index of fetuses of Manipuri population-A Base study. J Anat Soc India, 2001; 50(1):13-6

3. Berry A.C. and R.J. Berry. Epigenetic variation in the human cranium. J Anat. 1976; 101: 362380.

4. William P, Dyson M, Dussaak JE, Bannister LH, Berry MM, Collins P, Ferguson MWJ. Gray's Anatomy. In: Skeletal system, 38th Edn. Elbs with Churchill Livingston, London, Pp. 60712(1995)

5. Eickstedt E.V. The races and types of the western Himalayas. Man in India, 1926; 6: 237

6. Agron Rexhepi and Vjollca Meka. Cephalofacial morphological characteristics of Albanian Kosova population. International Journal of Morphology, 2008, 26(4):935-940

7. Stolovitsky J.P. and N.W. Todd. Head shape and abnormal appearance of Tympanic membrane. Otolaryngol Head, Neck Surg. 1990; 102: 322-325.

8. Cohen M.M. Jr. and S. Kreiborg. Cranial size and configuration in the Apert's Syndrome. J Craniofac Genec Dev Biol. 1994; 14: 95-102.

9. Rakshit H. K. A perspective for anthropometric work in India. In: Proceeding volume of summer school in Anthropology, Dalhausie, 1964. 
10. Ozaslan A, Iscan MY, Ozaslan I, Tugcu H, Koc S. Estimation of stature from body parts. Forensic Science International. 2003; 132:40-5.

11. Bidmos M and Asala S. Calcaneal measurement in estimation of Stature of South African blacks. American Journal of Physical Anthropology. 2005; 126:335-42.

12. Krishan Kewal. Estimation of stature from cephalo-facial anthropometry in north Indian Population. Forensic Science International 2008; 181 52.e1-52.e6

13. Ozaslan A, Koc S, Ozaslan I, Tugsu H. Estimation of stature from upper extremity. Mil Med. 2000; 171:288-91.

14. Simmons T, Jantz RL, Bass WM. Stature estimation from fragmentary femora: A revision of the Steele method. Journal of Forensic Science JFSCA. 1990; 35: 628-36.

15. Holland TD. Estimation of adult stature from fragmentary tibias. Journal of Forensic Science 1992, 37: 1223-9.

16. Zviagin VN and Eremenko EA. Determination of some somatic body dimensions by osteometric foot measurements. Sudanese Medical Ekspert. 2004; 47: 29-33.

17. Hrdlickka A. 1952. Practical Anthropometry. Fourth Edition. For-ward by T.D. Stewart. Philadelphia: The Wistar Institute of Anatomy and Biology.

18. Nagle E, Teibe U. Craniofacial anthropometry in a group of healthy Latvian residents. Acta Medica Litunica 2005; 12(1): 47-53.

19. Ngeow WC, Aljunid ST. Craniofacial anthropometric norms of Malays. Singapore Medical Journal 2009; 50(5):525-528.

20. Raji JM, Garba SH. Morphological Evaluation of Head and Face Shapes in a North - Eastern Nigerian Population. Australian Journal of Basic Applied Science 2010; 4(8):3338- 3341.

21. Oladipo GS, Okoh PD. Anthropometric Studies of Cephalic Length, Cephalic Breadth and Cephalic Indices of the Ibibios of Nigeria. Asian Journal of Medical Science2010; 2(3): 104106.

22. Mahajan A, Khurana BS. The Study of Cephalic Index in Punjabi Students. Journal of Punjab Academy of Forensic Medicine and Toxicology 2010; 10:24-26.

23. Maina MB, Shapu YC, Garba SH, Muhammad MA, Garba AM, Yaro AU et al. Assessment of Cranial Capacities in A North-Eastern Adult Nigerian Population. Journal of Applied Sciences 2011; 11:2662-2665.

24. Hossain MG, Saw A. Change in facial shape in two cohorts of Japanese adult female students twenty years apart. Singapore Medical Journal 2011; 52(1 1): 818-823.

25. Ilayperuma I. Evaluation of cephalic indices: A clue for Racial and Sex Diversity. International Journal of Morphology 2011; 29(1):112-117.

26. Sanjay Gupta, Patnaik. V. V. Gopichand, Subhash Kaushal, Sudha Chhabra, Vipin Garsa. Cranial Anthropometry in 600 North Indian Adults. Int J Anat Res, 2013; 02:115-18.

27. Oladipo G. S., Olotu J. E. \& Suleiman Y. Anthropometric studies of cephalic indices of the Ogonis in Nigeria. Asian J Med Sci. 2009; 1:15-7,

28. Williams P. L., Bannister L. H., Berry M. M., Collins P., Dyson M., Dussek J.E. Gray's Anatomy: The anatomical basis of medicine and surgery.38thEd. New York, Churchill Livingstone, 2000

29. Rabey G. P. Craniofacial morph analysis. Proc. R. Soc. Med., 1971;64:103-11,

30. Harper C., Krill J., Raven D. \& Jones N. Intracranial cavity volumes: a new method and its potential applications. Neuropathol. Appl Neurobiol., 1984; 10:25-32. 
31. Kondo S, Wakatsuki E. \& Shibagaki H. A. Somatometric study of the head and face in Japanese adolescents. Okajimas Folia Anat Jpn. 1999; 76:179-85,

32. Knutson B., Momenan R., Rawlings R. R., Fong G. W. \& Hommer D. Negative association of neuroticism with brain volume ratio in healthy humans. Biol Psychiatry 2001; 50:685-90;

33. Lobo SW, Chandrasekhar TS and Kumar S. Cephalic index of Gurung community of Nepal-An Anthropometric study. Kathmandu University Medical Journal.2005; 3 (11): 263-265.

34. Bharati S, Som S, Bharati P and Vasulu TS. Climate and head from in India. American Journal of Human Biology.2001; 13(5): 626-34.

35. Golalipour M. J., Jahanshahi M. \& Haidari K. Morphological evaluation of head in Turkman males in Gorgan-North of Iran. Int J Morphol., 2007; 25: 99-102,

36. Del Sol M. Cephalic index in a group of Mapuche individuals in the IX region of Chile. Int J Morphol, 2005;23:241-6,

37. García H. F. \& Lips M. W. Contribución al estudio del índice cefálico en chilenos. An Anat Norm, 1986a.; 4:120-3,

38. García H. F. \& Lips M. W. Variaciones del indice cefálico chilenos segun ascendencia. An Anat Norm, 1986b; 4:117-9,

39. Golalipour M. J. The variation of head shapes in 17-20 years old native Fars male in GorganNorth of Iran. Int J Morphol, 2006; 24:187-90,

40. Nakashima T. Brachycephalization in the head form of school girls in North Kyushu. J UOEH, 1986; 8:411-4.

\section{AUTHORS:}

1. Sumita Agarwal

2. S.K. Jain

3. S.K. Agarwal

\section{PARTICULARS OF CONTRIBUTORS:}

1. Demonstrator, Department of Anatomy, Teerthankar Mahaveer Medical College \& Research Centre, Moradabad.

2. Professor, Department of Anatomy, Teerthankar Mahaveer Medical College \& Research Centre, Moradabad.

3. Professor and Head, Department of Anatomy, Teerthankar Mahaveer Medical College \& Research Centre, Moradabad.

\section{NAME ADDRESS EMAIL ID OF THE CORRESPONDING AUTHOR:}

Dr. S.K. Jain,

Professor,

Department of Anatomy,

TMMC \& RC, Moradabad.

Email - drskjain2005@rediffmail.com

Date of Submission: 26/12/2013.

Date of Peer Review: 27/12/2013.

Date of Acceptance: 07/01/2014.

Date of Publishing: 17/01/2014. 